\title{
Introducing: Carbonates and Evaporites by Springer
}

\author{
James W. LaMoreaux
}

Published online: 13 February 2010

(C) Springer-Verlag 2010

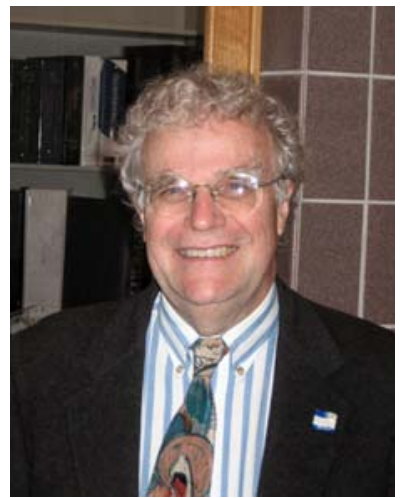

Welcome to the first issue of the international journal Carbonates and Evaporites (C\&E) published by Springer Science and Business Media. C\&E is being expanded to a quarterly publication with new issues released each year in March, June, September, and December. The journal's aims and scope have been enlarged to provide a broader range of coverage. Publication will be in full color. Springer will market and distribute the journal as part of its Earth Science program to increase the circulation and impact even further.

Founded and edited by Dr. Gerald Friedman and published by the Northeastern Science Foundation, the publication has a long history of publishing academic and technical research related to carbonates and evaporites. Since its inception in 1979, the journal has earned a reputation for academic excellence in international circles.

J. W. LaMoreaux $(\bowtie)$

1009 23rd Avenue, Tuscaloosa, AL 35401, USA

e-mail: carbonevap@yahoo.com
To provide continuity from one publisher to the next, copies of past issues of $C \& E$ have been uploaded to the Springer website for review and utilization.

It is a great honor to follow in the footsteps of Dr. Friedman as Editor-in-Chief. The editorial staff's and editorial board's plan is for the work of this journal to serve as an ongoing tribute to Dr. Friedman's example of dedication and commitment to the dissemination of research. To extend the vision of Dr. Friedman, the editorial board has been expanded.

The journal will also increase its emphasis on karst terrains. My father, Dr. Philip E. LaMoreaux, always wanted to publish a journal on karst. With the expansion of C\&E, his dream comes closer to fruition.

In addition to the emphasis on karst terrains and their unique problems, other topical areas will include hydrogeological aspects of carbonates, oil and gas exploration and research, economic geology related to carbonates and evaporites, mineralogy, stratigraphy and landforms, coastal studies in carbonate terrains, physical and engineering properties of carbonates and evaporites, astrogeology of evaporites, geotechnology and geoengineering issues, historical geology, practical applications of technologies in these environments, and other innovative research.

Articles, reports of research, and reviews of books and software related to all aspects of the study of carbonates and evaporites are welcomed. News contributions and letters to the editors may also be submitted. Please submit on line at: http://www.springer.com/earthsciences/geology/ journal/13146. A journal overview and instructions for authors are included on the website.

Carbonates and Evaporites is indexed by Academic Search, Chemical Abstracts Service (CAS), Current Contents/Physical, Chemical and Earth Sciences, Geobase, GeoRef, Google Scholar, OCLC, Petroleum Abstracts, 
Referativnyi Zhurnal, Science Citation Index, Science Citation Index Expanded (SciSearch), SCOPUS, Speleological Abstracts, and Summon by Serial Solutions, among other sources.

To enhance the quality of the publication, professionals who have an established record of academic and/or practical experience are invited to participate in the journal as peer reviewers. Please register your areas of expertise by visiting the publication submission website at: http://www. editorialmanager.com/caev/.

Carbonates and Evaporites provides an important resource for the study of critical environments. As the world copes with growing demands for sustainable expansion and resource utilization, interest in these areas will grow exponentially. The journal looks forward to continuing Dr. Friedman's legacy by playing a vital role in the process. 